\title{
Supply Chain Cooperation by Agreed Reduction of Behavior Variability: A Simulation-based Study
}

\author{
M.L. Chew \\ Hernández \\ Ind. Eng. Dept. \\ Tecnológico de \\ Estudios Superiores \\ de Coacalco \\ Coacalco, México \\ mchew@ \\ tesco.edu.mx
}

\author{
L. Viveros Rosas \\ Ind. Eng. Dept. \\ Tecnológico de \\ Estudios Superiores \\ de Coacalco \\ Coacalco, México \\ lviverosr@ \\ hotmail.com
}

\author{
R. F. Retes Mantilla \\ Management Dept. \\ Tecnológico de \\ Estudios Superiores \\ de Coacalco \\ Coacalco, México \\ retes1123@ \\ hotmail.com
}

\author{
G. J. Espinosa \\ Martínez \\ Management Dept. \\ Tecnológico de \\ Estudios Superiores \\ de Coacalco \\ Coacalco, México \\ gespinosam@ \\ yahoo.com.mx
}

\author{
V. Velázquez \\ Romero \\ Management Dept. \\ Tecnológico de \\ Estudios Superiores \\ de Coacalco \\ Coacalco, México \\ ing_ind_amb@, \\ hotmail.com
}

\begin{abstract}
Supply chain echelons normally base their operational decisions on average values of the parameters that depend on other members. However, in real-life operation the variability of said parameters decreases the link profits. Thus, a cooperative arrangement may be devised in which a link agrees to reduce the variability of its behavior to enhance the performance of other links, receiving compensation in return. This work shows the application of simulation and decision trees to assess the feasibility of this cooperation scheme, from the perspective of the central link of a three member supply chain. First, the operational parameters of the link are optimized for mean values of the variables set by adjacent members. Then, by simulating the system for different probability distributions of these variables, graphs of the expected link gain versus the variances of the distributions are plotted. The results are incorporated to decision trees to evaluate the collaboration feasibility. It was found that the increased variability of the behavior of one neighboring member decreases the benefit of lowering the variability of the behavior of the other. The manuscript closes with a discussion of the practical viability of this collaboration scheme.
\end{abstract}

Keywords-supply chain; uncertainty; collaboration; simulation

\section{INTRODUCTION}

A supply chain is the set of companies (named "links", "members" or "echelons") that participate in delivering a product to an end user, including activities ranging from raw material extraction, production, transporting and retail operations [1]. When the companies belong to different owners or parent organizations, each one doesn't normally have detailed information on the variables that depend on neighboring members (i.e. its supplier and customer). Thus, each link designs its operational polices based on average values of variables like size and arrival time of customer orders and supplier delivery times [2]. However, the real-life variability of these variables causes the link profits to be lower than planned [3]. A collaboration arrangement can be devised to alleviate this: a link commits to decrease the variability of its behavior so to benefit a neighboring member, receiving a payment from the latter in exchange. For example, in a chain of supplier-retailer-customer, the retailer can offer reduced prices to the customer in exchange for his commitment to make his purchases with an even quantity and frequency. Similarly, additional payments can be offered to the supplier if he commits to less variable delivery times, which can be provided by prioritizing inventory and transportation for this retailer. In this collaboration mode, customers and suppliers benefit the retailer by making their behavior less variable, without changing their average behavior. The size of the incentives that the retailer may offer for this partnership, however, depends on the benefits he reaps when the other links decrease their behavior variability.

This work shows the usage of simulation [4] and decision trees to evaluate the feasibility of the collaboration between supply chain members through a compromise of reducing their behavior variability. Simulation is used to assess the effect of the variability in the behavior of the upstream and downstream members on the performance of an intermediate link. The results are incorporated into a tree representing the decision of said link on whether to participate in an agreement of reduction of behavior variability. A simulation approach, such as presented here, allows a greater flexibility in the problem formulation than do the analytical expressions reported in the literature (for example in [3]).

\section{LITERATURE REVIEW AND JUSTIFICATION}

There is a vast body of research literature on supply chain collaboration. Empirical studies are shown in [5-7], dealing with the impact of inter-organizational systems on chain performance, and in [8], treating the effect of uncertainty and confidence. Collaborative supply chain performance has been analyzed in $[9,10]$, with the latter concluding that, in many cases, the collaboration only benefits the retailer. Planning and design models of the collaborative chain are shown in [11] for procurement planning, in [12] for cases in which the members have different manufacturing systems and in [13], where a link decision model incorporating cooperating members is shown. Meanwhile, the model of $[14,15]$ incorporated the internet to 
joint decision-making and [16] applied fuzzy logic to chain design. Models for chain cooperation under special situations have been developed. Synergies between suppliers are considered in [17]. In [18], the cooperation of a distributor with several vendors, which may transfer inventory between them was treated. A cooperative health service supply chain is modelled in [19], while the cases of making joint investments in infrastructure and advertising are shown, respectively in [20] and [21]. Other models treat the product-service case [22], include exchange rate uncertainty [23], advance notifications of returns in closed chains [24] and collaborative demand forecasting [25-27].

Several authors deal with the division of the collaboration benefits. Side payment calculation is approached through bargaining theory in [28-31]. The special case of supply chains with re-work is covered in [32], while [33] treats the effect of lying and misrepresentations on the contracts and [34] deals with gain sharing through wholesale pricing. A form of collaboration is the sharing of information. The effect on performance of different information sharing degrees is treated in [35]. In [36], authors showed how a global firm can improve its performance by sharing information with retailers. In [37], a model in which information on customer demand and adjustments of inventory position are shared through the chain is presented. In [38], authors discussed the convenience of sharing innovations with other links. Game theoretical models for the convenience for the retailer to share demand information are shown in $[39,40]$, the latter finding that the retailer is inclined to increase the uncertainty of the other links and in [41] authors concluded that, only when there are product returns, it is beneficial for the producer to share demand information with the retailers. Additionally, in [42] authors demonstrated that complete information sharing does not guarantee performance improvement. Analytical results of the impact of information sharing on the supply chain bullwhip effect are presented in [43-45]. The issue is also addressed statistically in [46] and through process control theory in [47]. Meanwhile, in [48] authors treated the case of chains with work returns and in [49] authors showed that, even with total information sharing, a residual bullwhip effect remains. Finally, chain performance with information sharing is contrasted to that of a vendor-managed inventory policy in [50, 51].

The above mentioned reports do not address supply chain cooperation through a links' agreement by which one member commits to decrease the variability of its behavior so to benefit another. While the benefits of this cooperation scheme may be lower than other cooperation forms treated in the literature, it has two qualities that render it appealing in practice. The first is that the member benefited by the variability reduction, does not need to disclose to the other the amount of this benefit. He just offers a payment for the variability reduction, which may or not be acceptable by the other. This makes it easy for the partners to find an agreement beneficial to both, without bargaining. The second advantage of this collaboration scheme is that, unlike other cooperation modes, it does not require the members to disclose information to each other. This is extremely important in practice, as many opportunities for cooperation between supply-chain members are hindered by the members' fear that the revealed information can prompt the other member to become a direct competitor. For example, the retailer may reasonably believe that if he reveals to its wholesaler that some of the customer's demand goes unsatisfied, the wholesaler may be tempted to launch a retail operation on its own. The collaboration scheme through payed reduction of behavior variability, with its minimal need for information revelation, allows an easy practical implementation, and thus may have a measurable impact on the operation of real supply chains.

\section{CASE STUDY DESCRIPTION}

A case study supply chain of supplier, retailer and customer is shown in Figure 1. The customers arrive to the retailer every $\Delta t_{C}$ time units and request the amount of product $Q_{C}$. If $Q_{C}$ is greater than the retailer's current inventory $\left(I_{T}\right)$, the sale is lost. The retailer's inventory policy is a point-of-reorder, continuous review scheme: when the value of $I_{T}$ is less than a minimum inventory $I_{T, M I N}$, he ask the supplier for a load of product of size $I_{T, M A X}$, which takes $\Delta t_{E}$ time units to arrive. For a given planning horizon, the retailer's profit $(G)$ can be calculated as

$$
G=P_{V} \times V_{T}-P_{D} \times V_{D}-C_{E} \times N_{E}-C_{I} \times \operatorname{Max}\left(I_{T}\right)
$$

Where:

$P_{V}=$ Unitary product sale price to the customer.

$P_{D}=$ Unitary product purchase price from the supplier.

$C_{I}=$ Cost of retailer inventory, per unit.

$C_{E}=$ Shipment cost from the supplier, per trip.

$V_{T}=$ Total sale of the retailer.

$V_{D}=$ Total sale of the supplier.

$N_{E}=$ Number of deliveries from the supplier to the retailer.

$\operatorname{Max}\left(I_{T}\right)=$ Maximum retailer inventory value during the planning horizon.

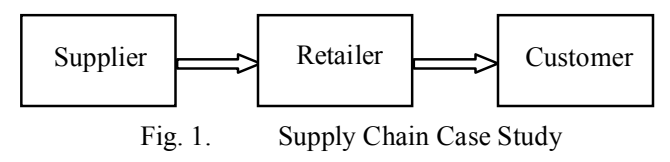

Equation (1) implies that the retailer pays the order delivery cost from the supplier. As mentioned in Section I, the retailer optimizes its operation parameters $\left(I_{T, M I N}\right.$ and $\left.I_{T, M A X}\right)$ so to maximize his profit $G$, based on average values of variables $\Delta t_{C}, Q_{C}$ and $\Delta t_{E}$, that depend on other chain members. However, the real-life variability of these parameters causes the retailer profit to be lower than the optimized value. Thus, the retailer can offer compensation to either supplier or customer (or both) for decreasing this variability. The maximum amount of this compensation depends on how much the variability reduction represents in increased retailer profits. In the following section, simulation is used to determine this maximum amount for a numerical case study.

The results are then introduced in a decision tree to evaluate the feasibility of paying for supplier collaboration. The following sections assume the values of $P_{V}=\$ 50 /$ item, $P_{D}=$ $\$ 30 /$ item, $C_{E}=\$ 1000 /$ trip and $C_{\Gamma}=\$ 50 /$ item and a simulation length of $1000 \mathrm{~h}$. 


\section{METHODOLOGY AND RESUltS}

\section{A. Simulation results}

The results presented were produced using a simple simulation model of the retailer's inventory, such as that shown in [52], coded in MS-Visual Basic. The retailer chooses the values of $I_{T, M I N}$ and $I_{T, M A X}$ to maximize his profits, assuming that the variables $\Delta t_{C}, Q_{C}$ and $\Delta t_{E}$ remain constant at their average values of, respectively, $\mathrm{E}\left[\Delta t_{C}\right], \mathrm{E}\left[Q_{C}\right]$ and $\mathrm{E}\left[\Delta t_{E}\right]$. The values of $I_{T, M I N}$ and $I_{T, M A X}$ so determined are named, respectively, $I_{T, M I N}{ }^{*}$ and $I_{T, M A X}{ }^{*}$. The influence diagram of this decision is shown in Figure 2. In these diagrams, doublebounded circles indicate variables with known value, rectangles stand for decisions and the hexagon represents the objective to be achieved [53]. Figure 2 emphasizes that the retailer, when selecting $I_{T, M I N}$ and $I_{T, M A X}$, considers only the average values of $\Delta t_{C}, Q_{C}$ and $\Delta t_{E}$.

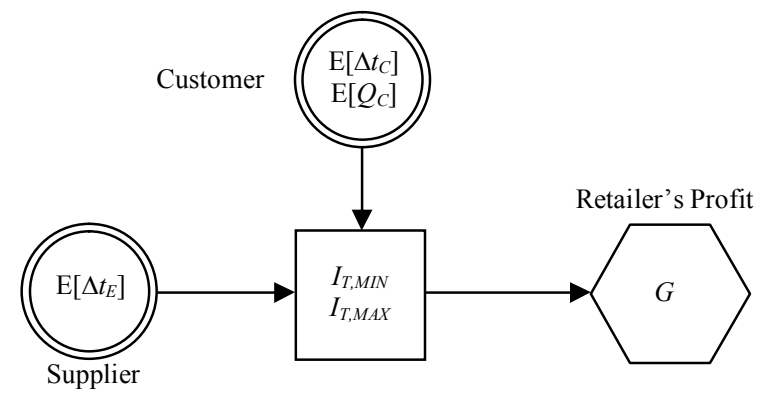

Fig. 2. Influence Diagram for Retailer's determination of $I_{T, M I N}$ and $I_{T, M A X}$

Setting the values $\Delta t_{C}=\mathrm{E}\left[\Delta t_{C}\right]=10 \mathrm{~h}, Q_{C}=\mathrm{E}\left[Q_{C}\right]=10$ items and $\Delta t_{E}=\mathrm{E}\left[\Delta t_{E}\right]=70 \mathrm{~h}$ and using simulation to evaluate different options of $I_{T, M I N}$ and $I_{T, M A X}$, the optimal values of $I_{T, M I N}{ }^{*}=60$ and $I_{T, M A X}{ }^{*}=200$ items are found. These produce a profit, in a $1000 \mathrm{~h}$ operation length, of $\$ 12^{\prime} 000$.

To evaluate the retailer loss due to the variability of $\Delta t_{C}$, $Q_{C}$, and $\Delta t_{E}$, different probability distributions are defined for these variables. The distributions retain the expected values previously set $\left(\mathrm{E}\left[\Delta t_{C}\right]=\mathrm{E}\left[Q_{C}\right]=10\right.$ and $\left.\mathrm{E}\left[\Delta t_{E}\right]=70\right)$, but differ in variance. For $\Delta t_{C}$ and $Q_{C}$, the probability distributions of Table I are defined, with Table II showing the corresponding distributions for $\Delta t_{E}$. In the tables, the notation $\operatorname{var}()$ refers to the variance of the variables for a probability distribution. The retailer's profit, when adhering to $I_{T, M I N}{ }^{*}$ and $I_{T, M A X}{ }^{*}$ and with $\Delta t_{C}, Q_{C}$ and $\Delta t_{E}$ following a probability distribution of Tables I and II, is calculated through simulation.

TABLE I. PROBABILITY DISTRIBUTIONS FOR $\Delta \mathrm{t}_{\mathrm{c}}$ AND $Q_{C}$

\begin{tabular}{|c|c|c|c|c|c|}
\hline \multirow{2}{*}{$\boldsymbol{x}_{\boldsymbol{i}}$ (value of $\Delta \boldsymbol{t}_{\boldsymbol{C}}$ or } & \multicolumn{5}{|c|}{$\mathbf{p}\left(\Delta \boldsymbol{t}_{\boldsymbol{C}}=\boldsymbol{x}_{\boldsymbol{i}}\right)$ or $\mathbf{p}\left(\boldsymbol{Q}_{\boldsymbol{C}}=\boldsymbol{x}_{\boldsymbol{i}}\right)$} \\
\cline { 2 - 6 } $\left.\boldsymbol{Q}_{C}\right)$ & Dist. I & Dist. II & Dist. III & Dist. IV & Dist. $\boldsymbol{V}$ \\
\hline 2 & 0 & 0 & 0 & 0.1 & 0.2 \\
\hline 6 & 0 & 0.1 & $1 / 3$ & 0.2 & 0.2 \\
\hline 10 & 1 & 0.8 & $1 / 3$ & 0.4 & 0.2 \\
\hline 14 & 0 & 0.1 & $1 / 3$ & 0.2 & 0.2 \\
\hline 18 & 0 & 0 & 0 & 0.1 & 0.2 \\
\hline $\mathrm{E}\left[\Delta t_{C}\right]=\mathrm{E}\left[Q_{C}\right]$ & 10 & 10 & 10 & 10 & 10 \\
\hline $\operatorname{var}\left(\Delta t_{C}\right)=\operatorname{var}\left(Q_{C}\right)$ & 0 & 3.2 & 10.66 & 19.2 & 32 \\
\hline
\end{tabular}

TABLE II. PROBABILITY DISTRIBUTIONS FOR $\Delta \mathrm{t}_{\mathrm{E}}$

\begin{tabular}{|c|c|c|c|c|}
\hline \multirow{2}{*}{$\boldsymbol{x}_{\boldsymbol{i}}\left(\right.$ value of $\left.\Delta \boldsymbol{t}_{\boldsymbol{E}}\right)$} & \multicolumn{4}{|c|}{$\mathbf{p}\left(\Delta \boldsymbol{t}_{\boldsymbol{E}}=\boldsymbol{x}_{\boldsymbol{i}}\right)$} \\
\cline { 2 - 5 } & Dist. I & Dist. II & Dist. III & Dist. I $\boldsymbol{~}$ \\
\hline 50 & 0 & 0 & 0.05 & 0.2 \\
\hline 60 & 0 & 0.1 & 0.3 & 0.2 \\
\hline 70 & 1 & 0.8 & 0.3 & 0.2 \\
\hline 80 & 0 & 0.1 & 0.3 & 0.2 \\
\hline 90 & 0 & 0 & 0.05 & 0.2 \\
\hline $\mathrm{E}\left[\Delta t_{E}\right]$ & 70 & 70 & 70 & 70 \\
\hline $\operatorname{var}\left(\Delta t_{E}\right)$ & 0 & 20 & 100 & 200 \\
\hline
\end{tabular}

Figure 3 shows the expected value of the retailer's profit $(\mathrm{E}[G])$, derived from 10'000 simulation replications, for all combinations of the probability distributions of Tables I and II; $\mathrm{E}[G]$ is plotted against the variance of $Q_{C}$, with the variance of $\Delta t_{C}$ shown parametrically for the curves. In Figures $3 \mathrm{a}-\mathrm{d}$, the variability of customer behavior is lower for the top curves (which are for probability distributions of low variance of time between arrivals) and for points closer to the left side of the figure (with low variance of the probability distribution of amount purchased). Similarly, the progression from Figure 3a to $3 \mathrm{~d}$ shows $\mathrm{E}[G]$ values for increasing variability in the behavior of the supplier (increasing variance of the probability distribution of supplier delivery times). The following observations can be done by perusing Figure 3:

1. In Figures 3a-d, the bundle of curves is wider to the left (where there is less variability of $Q_{C}$ ) than to the right. This means that decreasing the variability of $\Delta t_{C}$ (i.e. shifting from the lowest curve to the highest), has a greater impact the less variable $Q_{C}$ is. This is illustrated by comparing lengths $a$ to $a^{\prime}$ in Figure 3a.

2. In Figures 3a-d, the vertical distance between the highest and lowest points of a curve, is greater for the top curve (for $\left.\operatorname{var}\left(\Delta t_{C}\right)=0\right)$ than for the bottom one $\left(\operatorname{var}\left(\Delta t_{C}\right)=32\right)$. This is illustrated in Figure $3 \mathrm{a}$ by comparing the dimensions $b$ and $b^{\prime}$. This indicates that the decrease in variability of $Q_{C}$ has a bigger effect on $\mathrm{E}[G]$ the lower the variability of $\Delta t_{C}$ is.

These points are synthesized by stating that, regarding $\Delta t_{C}$ and $Q_{C}$, the value of decreasing the variability of one is greater the lower the variability of the other is.

The transit from Figure $3 \mathrm{a}$ to $3 \mathrm{~d}$ shows the effect of increasing the variability in supplier delivery time, $\Delta t_{E}$. From the curve bundle shape in these graphs, it can be noticed that, for an increased variability in $\Delta t_{E}$, the effect of changing the variability of $\Delta t_{C}$ and $Q_{C}$ becomes smaller. This can be measured quantitatively by calculating, for Figures $3 \mathrm{a}$ to $3 \mathrm{~d}$, the difference in $\mathrm{E}[G]$ between the point with the least variability in $Q_{C}$ and $\Delta t_{C}\left(\operatorname{var}\left(Q_{C}\right)=0\right.$ on the curve $\left.\operatorname{var}\left(\Delta t_{C}\right)=0\right)$ and that of the point with greatest variability in these variables $\left(\operatorname{var}\left(Q_{C}\right)=32\right.$ on the curve $\left.\operatorname{var}\left(\Delta t_{C}\right)=32\right)$. This difference is the impact of a reduced variability in the customer behavior. Doing this calculation for the four graphs of Figure 3, and plotting against the variance of $\Delta t_{E}$, produces Figure 4 . This plot shows that, as $\operatorname{var}\left(\Delta t_{E}\right)$ increases, the effect of reducing the variability of $Q_{C}$ and $\Delta t_{C}$ decreases. 

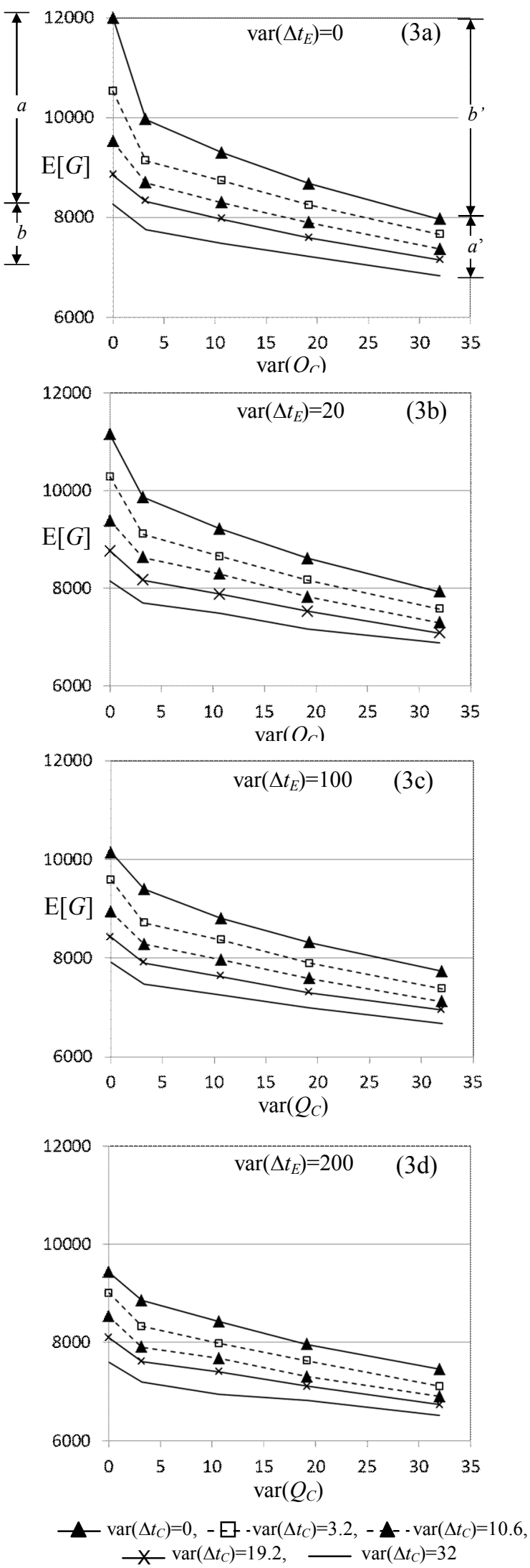

Fig. 3. $\quad \mathrm{E}[G]$ vs. variances of distributions in Tables I and II.

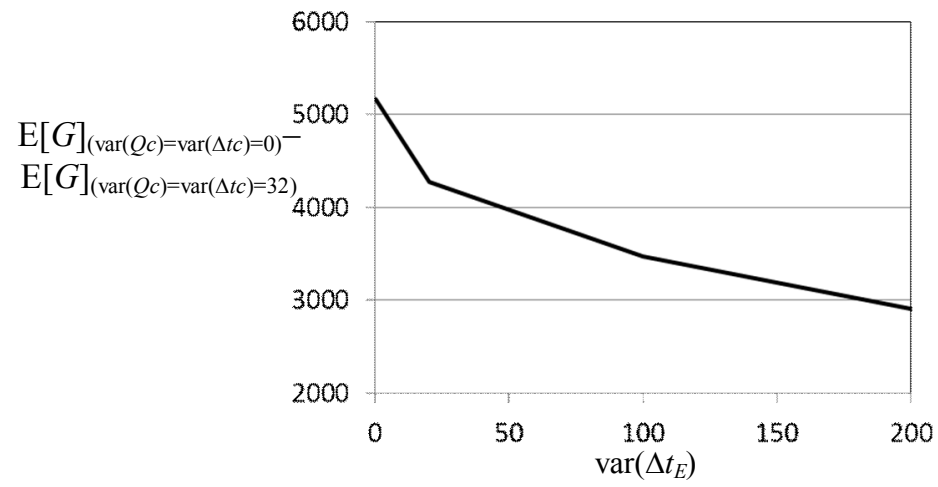

Fig. 4. Increase in $\mathrm{E}[G]$ by reducing the variability of $Q_{C}$ and $\Delta t_{C}$ vs. $\operatorname{var}\left(\Delta t_{E}\right)$

Similarly, Figure 5 shows the change in $\mathrm{E}[G]$ when the variability of $\Delta t_{E}$ drops from $\operatorname{var}\left(\Delta t_{E}\right)=200$ to $\operatorname{var}\left(\Delta t_{E}\right)=0$, for points with the same $\operatorname{var}\left(\Delta t_{C}\right)$ and $\operatorname{var}\left(Q_{C}\right)$ values. For example, the value for $\operatorname{var}\left(\Delta t_{C}\right)=\operatorname{var}\left(Q_{C}\right)=0$ is calculated by subtracting from the $\mathrm{E}[G]$ value of the point $\operatorname{var}\left(Q_{C}\right)=0$ on curve $\operatorname{var}\left(\Delta t_{C}\right)=0$ in Figure 3a, the value of $\mathrm{E}[G]$ of the analogous point of Figure 3d. A trend similar to that of Figure 4 can be seen in Figure 5: the greater the value of $\operatorname{var}\left(\Delta t_{C}\right)$ and $\operatorname{var}\left(Q_{C}\right)$, the smaller the worth of decreasing $\operatorname{var}\left(\Delta t_{E}\right)$.

It can be concluded that the more variable the behavior of the customer is, the smaller the benefit to be reaped from a reduction in the variability of the supplier's behavior. The same applies the other way around: as the supplier behavior grows variable, the benefit of decreasing the variability of the customer behavior shrinks. Thus, the potential benefit of getting the compromise of one member to reduce its behavior variability depends drastically on the variability of the other member's behavior.

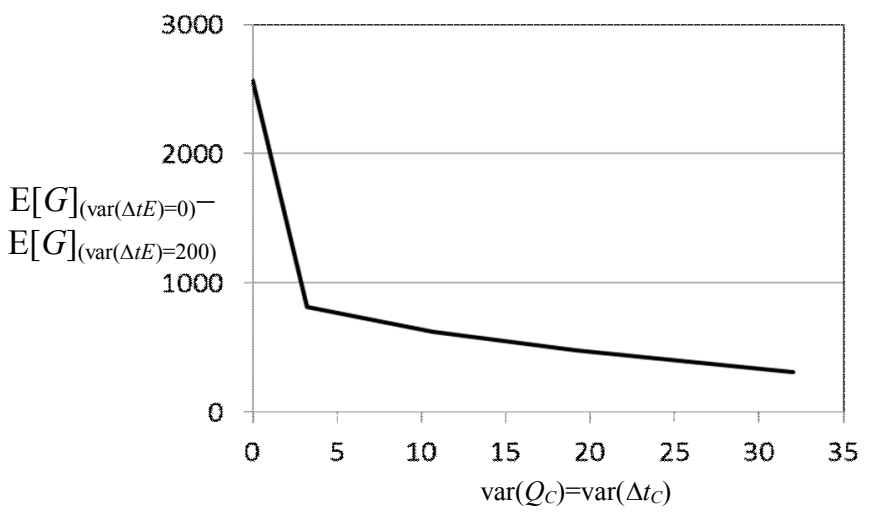

Fig. 5. Increase in $\mathrm{E}[G]$ by reducing the variability of $\Delta t_{E} \mathrm{vs}$. $\operatorname{var}\left(Q_{C}\right)$ and $\operatorname{var}\left(\Delta t_{C}\right)$

\section{B. Feasiblity of negotiating with the supplier}

The previous results are used to evaluate, from the retailer's perspective, the feasibility of negotiating with the supplier a payed reduction in the variability of the delivery time $\Delta t_{E}$. The retailer's decision of whether to pay the supplier for reducing the variability of $\Delta t_{E}$ is shown as a tree in Figure 6. In these trees, squares stand for decisions and circles represent 
uncertainties [53]. At the first decision square, "Negotiate with supplier" the retailer can choose either 'Yes' or 'No'. The alternative chosen influences the variability of $\Delta t_{E}$ : [Dist. $\left.\Delta t_{E}\right]_{\mathrm{OR}}$ represents the original (i.e. not negotiated) probability distribution of $\Delta t_{E}$ while [Dist. $\left.\Delta t_{E}\right]_{\mathrm{NE}}$ stands for the probability distribution of $\Delta t_{E}$ that the supplier agrees to maintain as a result of the deal with the retailer. It is understood that the variability of $\Delta t_{E}$ implied by [Dist. $\left.\Delta t_{E}\right]_{\mathrm{OR}}$ is greater than that of [Dist. $\left.\Delta t_{E}\right]_{\mathrm{NE}}$. The retailer's profit is written to the extreme right of the tree. It can be seen that this profit is affected by the probability distributions of $Q_{C}$ and $\Delta t_{C}$, whose variability depends on the customer. The deal between the retailer and supplier implies that the former pays the latter an amount $c_{N}$ $(\$)$, so the retailer's profit for the top branch is $G-c_{N}$.

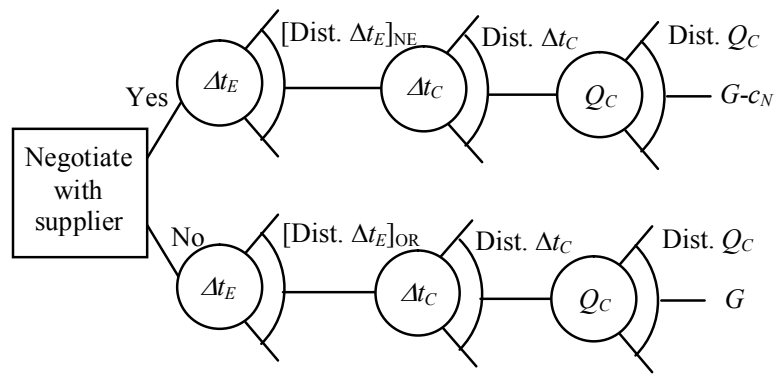

Fig. 6. Retailer's decision tree on whether to negotiate a reduction in the variability of $\Delta t_{E}$

The greatest value of $c_{N}$ that the retailer can pay for the supplier's cooperation can be determined by substituting in the tree the relevant data from Figure 3. For example, for a low variability in customer's behavior $\left(\operatorname{var}\left(Q_{C}\right)=\operatorname{var}\left(\Delta t_{C}\right)=3.2\right)$, the highest value the retailer can pay for reducing the variability of $\Delta t_{E}$ from $\operatorname{var}\left(\Delta t_{E}\right)=200$ to $\operatorname{var}\left(\Delta t_{E}\right)=20$ is $\$ 323$. If, on the other hand, there is a high variability in the customer's behavior $\left(\operatorname{var}\left(Q_{C}\right)=\operatorname{var}\left(\Delta t_{C}\right)=32\right)$ the maximum value of to pay for such variability reduction is only $\$ 109$.

\section{CONCLUSIONS}

Normally the links of a supply chain design their operation based on average values of the parameters set by other chain members, and, as a result of the real variability of said parameters, their profits are diminished. The aim of this work is to explore the feasibility of a form of supply chain collaboration, consisting of the links reducing the variability of their behavior so to benefit another, in exchange for a monetary compensation. A key factor for the operability of this cooperation scheme is how much the profit of the members improves by such variability reduction. This work shows the use of simulation to determine this improvement, for a case study of supplier-retailer-customer. The retailer designs its operation using average values of the variables depending on other members and then, by simulating different probability distributions for these variables, the variability impact on the retailer's profits is calculated. For the central link, the value of reducing the variability of the behavior of one neighboring member (upstream or downstream) is strongly related to the variability of the behavior of the other. Reducing the variability of the behavior of either member is more valuable when the behavior of the other isn't widely variable. If both members show a very variable behavior, a collaboration scheme with only one of them appears to be of little value. In this case, some reduction of the variability of both members' behavior should be sought. While the feasibility conditions of this scheme seem somewhat restrictive, it should be noted that, given the practical advantages of this collaboration scheme (i.e. natural way of cutting win-win contracts, no information disclosure needed), a situation in which the retailer can get behavior variability reduction commitments from both neighboring links, is not farfetched. However, as the retailer must pay for the collaboration of both neighbors, an analysis via simulation and decision trees, such as presented here, can be done to determine how much he can pay while still coming ahead.

\section{REFERENCES}

[1] S. Chopra, P. Meindl, Supply Chain Management, Third Edition, Pearson Education, 2007

[2] C. Harrell, B. K. Ghosh, R. O. Bowden, Simulation Using Promodel, Third Edition, Mc Graw Hill, 2012

[3] X. Fang, C. Zhang, D. J. Robb, J. D. Blackburn, "Decision support for lead time and demand variability reduction", Omega, Vol. 41, pp. 390396, 2013

[4] J. Banks, J. S. Carson II, B. L. Nelson, D. M. Nicol, Discrete Event System Simulation, Fifth Edition, Pearson Education, 2010

[5] W. G. Qu, Z. Yang, "The effect of uncertainty avoidance and social trust on supply chain collaboration", Journal of Business Research, Vol. 68, No. 5, pp. 911-918, 2015

[6] J. Luo, A. Y. -L. Chong, E. W. T. Ngai, M. J. Liu, "Green Supply Chain Collaboration implementation in China: The mediating role of guanxi", Transportation Research Part E: Logistics and Transportation Review, Vol. 74, pp. 37-49, 2015

[7] J. Luo, A. Y. -L. Chong, E. W. T. Ngai, M. J. Liu, "Green Supply Chain Collaboration implementation in China: The mediating role of guanxi", Transportation Research Part E: Logistics and Transportation Review, Vol. 71, pp. 98-110, 2014

[8] D. J. -F. Jeng, "Generating a causal model of supply chain collaboration using the fuzzy DEMATEL technique", Computers and Industrial Engineering, Vol. 87, pp. 283-295, 2015

[9] E. Ciancimino, S. Cannella, M. Bruccoleri, J. M. Framinan, "On the Bullwhip Avoidance Phase: The Synchronised Supply Chain", European Journal of Operational Research, Vol. 221, No. 1, pp. 49-63, 2012

[10] R. Cigolini, M. Pero, T. Rossi, A. Sianesi, "Linking supply chain configuration to supply chain performance: A discrete event simulation model", Simulation Modelling Practice and Theory, Vol. 40, pp. 1-11, 2014

[11] R. Guillaume, C. Thierry, B. Grabot, "A decision support tool for procurement planning process under uncertainty", IFAC Proceedings Volumes, Vol. 44, No. 1, pp. 1590-1595, 2011

[12] R. Guillaume, B. Grabot, C. Thierry, "Management of the risk of backorders in a MTO-ATO/MTS context under imperfect requirements", Applied Mathematical Modelling, Vol. 37, Nos. 16-17, pp. $8060-8078,2013$

[13] R. Guillaume, G. Marques, C. Thierry, D. Dubois, "Decision support with ill-known criteria in the collaborative supply chain context", Engineering Applications of Artificial Intelligence, Vol. 36, pp. 1-11, 2014

[14] O. Kwon, G. P. Im, K. C. Lee, "MACE-SCM: A multi-agent and casebased reasoning collaboration mechanism for supply chain management under supply and demand uncertainties", Expert Systems with Applications, Vol. 33, No. 3, pp. 690-705, 2007 
[15] O. Kwon, G. P. Im, K. C. Lee, "An agent-based web service approach for supply chain collaboration", Scientia Iranica, Vol. 18,No. 6, pp. $1545-1552,2011$

[16] R. Xu, X. Zhai, "Optimal models for single-period supply chain problems with fuzzy demand", Information Sciences, Vol. 178, No. 17, pp. 3374-3381, 2008

[17] M. A. Sodenkamp, M. Tavana, D. Di Caprio, "Modeling synergies in multi-criteria supplier selection and order allocation: An application to commodity trading", European Journal of Operational Research, Vol. 254, No. 3, pp. 859-874, 2016

[18] S. Gavirneni, "Benefits of co-operation in a production distribution environment", European Journal of Operational Research, Vol. 130, No. 3, pp. 612-622, 2001

[19] A. Villa, D. Bellomo, I. Cassarino, "Uncertain demand and supply networks management: application to a regional health care service", IFAC Proceedings Volumes, Vol. 38, No. 1, pp. 30-35, 2005

[20] B. Marchi, J.M. Ries, S. Zanoni, C. H. Glock, "A joint economic lot size model with financial collaboration and uncertain investment opportunity", International Journal of Production Economics, Vol. 176, pp. 170-182, 2016

[21] Z. Huang, S. X. Li, "Co-op advertising models in manufacturer-retailer supply chains: A game theory approach", European Journal of Operational Research, Vol. 135, No. 3, pp. 527-544, 2001

[22] C. Durugbo, X. Wang, "Network-oriented Uncertainty Evaluation of Industrial Product-service Collaborative Readiness", Procedia CIRP, Vol. 16, pp. 229-234, 2014

[23] J. -Y. Lee, L. Ren, "Vendor-managed inventory in a global environment with exchange rate uncertainty", International Journal of Production Economics, Vol. 130, No. 2, pp. 169-174, 2011

[24] T. Hosoda, S. M. Disney, S. Gavirneni, "The impact of information sharing, random yield, correlation, and lead times in closed loop supply chains", European Journal of Operational Research, Vol. 246, No. 3, pp. 827-836, 2015

[25] M. R. Galbreth, M. Kurtuluş, M. Shor, "How collaborative forecasting can reduce forecast accuracy", Operations Research Letters, Vol. 43, No. 4, pp. 349-353, 2015

[26] X. Zhu, S. K. Mukhopadhyay, X. Yue, "Role of forecast effort on supply chain profitability under various information sharing scenarios", International Journal of Production Economics, Vol. 129, No. 2, pp. 284291, 2011

[27] U. Ramanathan, "Aligning supply chain collaboration using Analytic Hierarchy Process", Omega, Vol. 41, No. 2, pp. 431-440, 2013

[28] M. Leng, A. Zhu, "Side-payment contracts in two-person nonzero-sum supply chain games: Review, discussion and applications", European Journal of Operational Research, Vol. 196, No. 2, pp. 600-618, 2009

[29] H. -M. Song, H. Yang, A. Bensoussan, "Optimizing production and inventory decisions in a supply chain with lot size, production rate and lead time interactions", Applied Mathematics and Computation, Vol. 224, pp. 150-165, 2013

[30] G. Xu, B. Dan, X. Zhang, C. Liu, "Coordinating a dual-channel supply chain with risk-averse under a two-way revenue sharing contract", International Journal of Production Economics, Vol. 147, Part A, pp. $171-179,2014$

[31] Z. Lin, C. Cai, B. Xu, "Supply chain coordination with insurance contract", European Journal of Operational Research, Vol. 205, No. 2, pp. 339-345, 2010

[32] Y. Zheng, S. Zhang, X. Chen, F. Liu, "Application of Modified Shapley Value in Gains Allocation of Closed-loop Supply Chain under ThirdParty Reclaim", Energy Procedia, Vol. 5, pp. 980-984, 2011

[33] B. Yan, T. Wang, Y. -P. Liu, Y. Liu, "Decision analysis of retailerdominated dual-channel supply chain considering cost misreporting", International Journal of Production Economics, Vol. 178, pp. 34-41, 2016

[34] Y. Wei, T. -M. Choi, "Mean-variance analysis of supply chains under wholesale pricing and profit sharing schemes", European Journal of Operational Research, Vol. 204, No. 2, pp. 255-262, 2010
[35] D. W. Cho, Y. H. Lee, "The value of information sharing in a supply chain with a seasonal demand process", Computers and Industrial Engineering, Vol. 65, No. 1, pp. 97-108, 2013

[36] S. Kumar, M. Yang, D. M. Strike, "Assessing effect of global inventory planning with enterprise-wide information for a large manufacturer", Journal of Manufacturing Systems, Vol. 34, pp. 34-42, 2015

[37] F. Costantino, G. Di Gravio, A. Shaban, M. Tronci, "The impact of information sharing on ordering policies to improve supply chain performances", Computers and Industrial Engineering, Vol. 82, pp. 127142,2015

[38] E. S. Nasr, M. D. Kilgour, H. Noori, "Strategizing niceness in coopetition: The case of knowledge exchange in supply chain innovation projects", European Journal of Operational Research, Vol. 244, No. 3, pp. 845-854, 2015

[39] J. Zhang, J. Chen, "Coordination of information sharing in a supply chain", International Journal of Production Economics, Vol. 143, No. 1, pp. $178-187,2013$

[40] J. -C. Wang, H. -S. Lau, A. H. L. Lau, "How a retailer should manipulate a dominant manufacturer's perception of market and cost parameters", International Journal of Production Economics, Vol. 116, No. 1, pp. 43-60, 2008

[41] T. -M. Choi, J. Li, Y. Wei, "Will a supplier benefit from sharing good information with a retailer?", Decision Support Systems, Vol. 56, pp. 131-139, 2013

[42] Y. Zhao, X. Zhao, "On human decision behavior in multi-echelon inventory management", International Journal of Production Economics, Vol. 161, pp. 116-128, 2015

[43] T. Hosoda, S. M. Disney, "On variance amplification in a three-echelon supply chain with minimum mean square error forecasting", Omega, Vol. 34, No. 4, pp. 344-358, 2006

[44] Y. Ouyang, X. Li, "The bullwhip effect in supply chain networks", European Journal of Operational Research, Vol. 201, No. 3, pp. 799810,2010

[45] Y. Ouyang, "The effect of information sharing on supply chain stability and the bullwhip effect", European Journal of Operational Research, Vol. 182, No. 3, pp. 1107-1121, 2007

[46] J. G. Kim, D. Chatfield, T. P. Harrison, J. C. Hayya, "Quantifying the bullwhip effect in a supply chain with stochastic lead time", European Journal of Operational Research, Vol. 173, No. 2, pp. 617-636, 2006

[47] J. Dejonckheere, S. M. Disney, M. R Lambrecht, D. R. Towill, "The impact of information enrichment on the Bullwhip effect in supply chains: A control engineering perspective", European Journal of Operational Research, Vol. 153, No. 3, pp. 727-750, 2004

[48] D. C. Chatfield, A. M. Pritchard, "Returns and the bullwhip effect", Transportation Research Part E: Logistics and Transportation Review, Vol. 49, No. 1, pp. 159-175, 2013

[49] M. S. Sodhi, C. S. Tang, "The incremental bullwhip effect of operational deviations in an arborescent supply chain with requirements planning", European Journal of Operational Research, Vol. 215, No. 2, pp. 374382,2011

[50] D. Sabitha, C. Rajendran, S. Kalpakam, H. Ziegler, "The value of information sharing in a serial supply chain with $\mathrm{AR}(1)$ demand and non-zero replenishment lead times", European Journal of Operational Research, Vol. 255, No. 3, pp. 758-777, 2016

[51] X. Yuan, L. Shen, J. Ashayeri, "Dynamic simulation assessment of collaboration strategies to manage demand gap in high-tech product diffusion", Robotics and Computer-Integrated Manufacturing, Vol. 26, No. 6, pp. 647-657, 2010

[52] S. M. Ross, Simulation, Elsevier Academic Press, 2006

[53] R. A. Howard, A. E. Abbas, Foundations of Decision Analysis, Pearson Education, 2016 